\title{
Quantitative Computational Thermochemistry of Transition Metal Species ${ }^{\dagger}$
}

\author{
Nathan J. DeYonker, ${ }^{\ddagger}$ Kirk A. Peterson, ${ }^{\S}$ Gideon Steyl, ${ }^{*}$ Angela K. Wilson, ${ }^{\ddagger}$ and \\ Thomas R. Cundari*, \\ Center for Advanced Scientific Computing and Modeling (CASCaM), Department of Chemistry, University of \\ North Texas, Denton, Texas 76203, Department of Chemistry, Washington State University, Pullman, \\ Washington 99164, and Department of Chemistry, The University of the Free State, \\ Bloemfontein, South Africa 9301
}

Received: February 22, 2007

\begin{abstract}
The correlation consistent Composite Approach (ccCA), which has been shown to achieve chemical accuracy $\left( \pm 1 \mathrm{kcal} \mathrm{mol}^{-1}\right)$ for a large benchmark set of main group and s-block metal compounds, is used to compute enthalpies of formation for a set of $173 \mathrm{~d}$ transition metal species. The training set includes a variety of metals, ligands, and bonding types. Using the correlation consistent basis sets for the $3 \mathrm{~d}$ transition metals, we find that gas-phase enthalpies of formation can be efficiently calculated for inorganic and organometallic molecules with ccCA. However, until the reliability of gas-phase transition metal thermochemistry is improved, both experimentally and theoretically, a large experimental training set where uncertainties are near $\pm 1 \mathrm{kcal}$ $\mathrm{mol}^{-1}$ (akin to commonly used main group benchmarking sets) remains an ambitious goal. For now, an average deviation of $\pm 3 \mathrm{kcal} \mathrm{mol}^{-1}$ appears to be the initial goal of "chemical accuracy" for ab initio transition metal model chemistries. The ccCA is also compared to a more robust but relatively expensive composite approach primarily utilizing large basis set coupled cluster computations. For a smaller training set of eight molecules, ccCA has a mean absolute deviation (MAD) of $3.4 \mathrm{kcal} \mathrm{mol}^{-1}$ versus the large basis set coupled-clusterbased model chemistry, which has a MAD of $3.1 \mathrm{kcal} \mathrm{mol}^{-1}$. However, the agreement for transition metal complexes is more system dependent than observed in previous benchmark studies of composite methods and main group compounds.
\end{abstract}

\section{Introduction}

From catalysis to advanced materials to biomedical applications, chemists have long sought new materials and processes that harness the unique properties of transition metals (TMs or $\mathrm{tm})$. It is the great chemical diversity of these elements in terms of their ability to stabilize distinctly different structural, electronic, and chemical states that lies at the heart of their utility in nature and industry. It is this "chemical diversity" that is also responsible for many of the major challenges that persist in computational TM chemistry, particularly vis-à-vis thermodynamic properties. The thermodynamic description of TM compounds also has significant experimental impediments, including material instability, incomplete combustion, and nonstoichiometric oxide formation. Hence, an efficient computational strategy for the calculation of accurate TM thermodynamics could significantly accelerate the development of new TM-based materials and processes.

$\mathrm{Ab}$ initio techniques ${ }^{1}$ for the calculation of chemically accurate thermodynamics (i.e., $\pm 1-2 \mathrm{kcal} \mathrm{mol}^{-1}$ ) for main group species have been widely investigated, for example, Gaussian- $n,{ }^{2-5}$ the complete basis set (CBS- $n$ ) methods, ${ }^{6-9}$ the focal point method, ${ }^{10-17} \mathrm{~W} n$ methods, ${ }^{18-21}$ the HEAT method, ${ }^{22,23}$ the composite method of Dixon, Feller, Peterson, and coworkers, ${ }^{24-32}$ and the newly developed correlation consistent composite approach (ccCA) ${ }^{33-36}$ Yet to our knowledge, no methodical thermochemical analysis of ab initio model chem-

\footnotetext{
$\dagger$ Part of the "Thom H. Dunning, Jr., Festschrift".

University of North Texas.

$\S$ Washington State University.

\# The University of the Free State.
}

istries for a series of chemically diverse TM complexes on the scale of the G2 or G3 test sets ${ }^{37}$ has been reported, though the most ambitious to date may be represented by the study of 62 TM-containing molecules by Furche and Perdew ${ }^{38}$ and used by Truhlar and co-workers. ${ }^{39}$ However, the Furche and Perdew study did not specifically address benchmarking overall energetic or thermodynamic quantities but instead focused on equilibrium geometries, harmonic vibrational frequencies, and bond dissociation energies of common molecular bonding types.

Computational TM thermochemistry results are difficult to calibrate in the face of conflicting experimental measurements. Some studies employ subsets of complexes and reactions that are not sufficiently diverse in size or bonding type, or both. However, progress in ab initio TM thermodynamics has been made. Recent examples include the studies by Grimme and coworkers using spin component scaled Møller-Plesset secondorder perturbation (MP2) and third-order (MP3) methods for a selection of organometallic complexes for prototypical reactions such as hydrogenation and ligand loss..$^{40,41}$ Nielsen and Allendorf used isogyric reactions to calculate enthalpies of formation of several chlorides and fluorides of chromium, manganese, and iron using a coupled cluster with single and double excitations and perturbative triples $[\mathrm{CCSD}(\mathrm{T})] /$ density functional theory (DFT) approach. ${ }^{42,43}$ In a very interesting paper, Quintal et al. ${ }^{44}$ assess the performance of several functionals for prototypical reactions of later, heavier TMs (e.g., $\mathrm{Pd}$ and $\mathrm{Rh}$ ) in relation to post-Hartree-Fock methods such as MP2 and $\operatorname{CCSD}(\mathrm{T})$; modification of the admixture of Hartree-Fock exchange in hybrid functionals is found to be beneficial, but unfortunately system dependent. 
Density functional theory (DFT) has been applied to the study of TM species with varying success. A recent contribution in our group ${ }^{45}$ showed calculated errors in gas-phase enthalpies of formation for a set of $26 \mathrm{TM}$ complexes with DFT and effective-core potential basis sets to be as large as $240 \mathrm{kcal}$ $\mathrm{mol}^{-1}$ ! The aforementioned study by Truhlar and co-workers ${ }^{39}$ evaluated many different functionals for an assortment of small metal molecules and cations, including some main group metal compounds, and found the G96LYP functional and their newly developed MPWLYP1M and M05 ${ }^{46}$ functionals performed well. The nonsystematic nature of DFT is omnipresent: as for different types of inorganic systems, different functionals perform radically different when computing different properties. Unfortunately, even the newest DFT functionals ${ }^{38,39,46}$ still commonly show errors from 5-18 kcal mol${ }^{-1}$, unacceptable errors from a main-group thermochemistry standpoint.

The recently created ccCA model chemistry obviates ad hoc corrections, such as the high-level correction (HLC) of the Gn methods, and entails a sequence of computations to calculate thermodynamic quantities that mimic those at an effective complete basis set (CBS) limit, nonfrozen-core CCSD(T) level of theory, but at a much reduced computational cost. Apart from theoretical objections to an HLC in an otherwise ab initio methodology, it is not clear how transferable an HLC derived for main group compounds would be for TM complexes. Also, a uniform collection of "Pople-style" basis sets allowing Gn methods to be applicable to TM species has not yet been created. Even if such basis sets become available, differential electron correlation effects between TM atomic and TM molecular computations (as would be examined when computing molecular $\left.\Delta H_{\mathrm{f}}\right)$ will be significantly larger for the $\mathrm{G} n$ method, requiring a reparameterized HLC to even further compensate for basis set deficiencies. ${ }^{33} \mathrm{G} n$-like variants have sparingly been used to compute energies of TM systems. ${ }^{47-49}$

The philosophy behind creating the ccCA model chemistry is to efficiently provide energies in an easy-to-use "black box" manner akin to the $\mathrm{G} n$ methods, but similar in accuracy to more expensive large basis coupled cluster approaches. The ccCA, calibrated against $>375$ main group energies, ${ }^{35}$ has been shown to yield chemically accurate thermodynamic predictions for s-block metal complexes (compounds that can be difficult to model with $\mathrm{G} n$ and $\mathrm{W} n$ composite methods $)^{50,51}$ without the need to modify the ccCA scheme. ${ }^{36,52}$ Inspired by this success, we sought to extend the ccCA methodology to TM (d-block) complexes. This paper reports our first efforts toward this challenging goal for a series of first-row TM compounds, which are of a size amenable to computations and for which the experimental errors in their $\Delta H_{\mathrm{f}}$ are reasonably well calibrated.

\section{Theoretical Methods}

The main thermodynamic property of interest in our investigation is the gas-phase enthalpy of formation at STP, $\Delta H_{\mathrm{f}}{ }^{\circ}(298.15 \mathrm{~K})$. As is well-known, the calculation of enthalpies of formation from theoretical atomization energies is one of the most stringent tests of a model chemistry. ${ }^{3,32,53,54}$ Target molecules with known $\Delta H_{\mathrm{f}}$ should be chosen to encompass a range of important chemical states inherent to TM chemistry (for example, different coordination numbers; Werner-type coordination complexes and organometallics; early, middle, and late metals in the transition series; hard and soft donor ligands; and so forth) while still maintaining a molecule size that permits the detailed calculations needed for this research. Unfortunately, finding reliable experimental enthalpies of formation for modestly sized TM compounds is currently quite difficult. While the authors of the $\mathrm{G} n$ methods stringently excluded any experimental energy with an uncertainty greater than $\pm 1 \mathrm{kcal}$ $\mathrm{mol}^{-1}$ from their main group test sets, ${ }^{37}$ the dearth of experimental TM enthalpies of formation precludes such a rigid paradigm. Some of the values used in this study have experimental error bars as large as $\pm 10 \mathrm{kcal} \mathrm{mol}^{-1}$. Uncertainties in enthalpies of formation are also quite large for the TM atoms, averaging $1.2 \mathrm{kcal} \mathrm{mol}^{-1}$, with uncertainties $1 \mathrm{kcal} \mathrm{mol}^{-1}$ or larger for $\mathrm{Ti}, \mathrm{V}, \mathrm{Cr}, \mathrm{Mn}$, and $\mathrm{Ni}$, compared with an average of $0.2 \mathrm{kcal} \mathrm{mol}^{-1}$ for all atoms from $\mathrm{H}$ to $\mathrm{Na}$. It is thus apparent that there are many layers of difficulty to unravel when systematically developing a robust composite approach for a large set of TM-containing molecules; the present contribution describes a first step in this direction.

The steps in the ccCA-tm protocol for computing TM thermodynamics are mostly identical to the formulation for sand p-block compounds. All ccCA computations are run in Gaussian 03 with unrestricted Hartree-Fock (UHF) wave functions for open-shell systems. ${ }^{55}$ The steps in the ccCA-tm protocol are as follows:

1. An equilibrium structure is obtained from DFT (B3LYP) in conjunction with the $\operatorname{SBKJC}(\mathrm{d})$ effective core potentials (ECPs) for $\mathrm{TMs}^{56}$ and 6-31G(d) basis sets for main group elements. This step employs DFT calculations to give accurate geometrical structures in a timely fashion.

2. The optimized structure is used to confirm that the stationary point obtained is a true minimum (i.e., positive definite Hessian) and also to compute the harmonic vibrational frequencies, which are scaled by a factor of $0.9684^{57}$ to take into account known deficiencies of the harmonic approximation, from which zero point energy and enthalpy corrections $[\Delta E(\mathrm{ZPE})]$ are obtained. Thermal corrections and ZPEs are used to compute enthalpies of formation in the standard procedure of Curtiss and co-workers. ${ }^{53}$

3. A series of single point calculations are then performed at higher levels of theory using main group correlation consistent basis sets ${ }^{58-65}$ and the TM correlation consistent basis sets of Balabanov and Peterson. ${ }^{66}$ The initial energy of the system is calculated by extrapolating MP2 perturbation theory single point correlation energies with the aug-cc-pVTZ and aug-cc-pVQZ basis sets [aug-cc-pV(n+d)Z basis sets for $\mathrm{Cl}]^{59,67}$ to the CBS limit. While it is well-known that HF energies converge to the CBS limit in an exponentially decaying fashion with increasing $\zeta$ level, ${ }^{68-70}$ MP2 correlation energies can have multiple CBS functional forms. While extrapolating total energies using the Schwartz $\left(1 / l_{\max }\right)^{4}$ two-point CBS function ${ }^{71-77}$

$$
E\left(l_{\max }\right)=E_{\mathrm{CBS}}+\frac{B}{\left(l_{\max }+\frac{1}{2}\right)^{4}}
$$

where $l_{\max }$ is the maximum angular momentum of the basis functions, which previously has been shown to be the most accurate two-point CBS extrapolation for main group ccCA energies,${ }^{35}$ preliminary results indicated that differences in $\mathrm{HF}$ and MP2 convergence behavior were exacerbated for TM systems. Using two-point HF fits to estimate the CBS HF energy adds another potential source of error to the ccCA-tm total energies. Rather than compute costly HF/aug-cc-pV5Z energies, we have based the HF basis set extrapolation on the formula recommended by Halkier and co-workers. ${ }^{68}$ Their investigation concluded that for a two-point extrapolation of the HF energy, an exponential fit in the standard exponential equation

$$
E^{\mathrm{HF}}(n)=E_{\mathrm{CBS}}^{\mathrm{HF}}+B \exp (-\alpha n)
$$


where $n$ is the cardinal number of the basis set $(n=2$ for DZ, 3 for TZ, etc.) gave the best statistical fit to numerical HF energies when a fixed $\alpha$ parameter of 1.63 was used. However, this approach gave a better estimate of the $n+1$ HF energy rather than the HF CBS limit. Indeed for a subset of atomic and molecular energies, the energy obtained using eq 1.2 with $n=2$ and 3 (TQ) agreed with the HF/aug-cc-pV5Z energy to better than $1 \mathrm{mE}_{\mathrm{h}}$. Halkier and co-workers have shown that augcc-pV5Z HF energies are generally within $1 \mathrm{mE}_{\mathrm{h}}$ of numerical HF energies. ${ }^{68}$

It is also important to note that, for the TM cc-pVXZ basis sets developed by Balabanov and Peterson, the $l_{\max }$ referred to in eq 1.1 is one greater than the cardinal number or $\zeta$ level used. When computing the MP2 CBS energy, "TQ" TM energies will also be fit in the fashion of a "Q5" main group CBS fit; that is, $l_{\max }=n+1$, which implicitly assumes that $\mathrm{TM}$ energies will be less converged to the CBS limit at a given $\zeta$ level than their main group counterparts. A physical explanation for this is that correlation consistent basis sets with valence $\mathrm{d}$ functions may have higher angular momentum shells far less saturated than s- and p-block counterparts. For molecular TM computations, it remains to be seen if the basis set convergence is dominated by the TM atoms, and work is being carried out in our lab to further address the CBS convergence of TM species. The Schwartz $\left(l_{\max }\right)^{-3}$ fit utilized in many other thermochemical model chemistries, for example, HEAT, ${ }^{23} \mathrm{~W} 1$, and $\mathrm{W} 2,{ }^{19}$

$$
E\left(l_{\max }\right)=E_{\mathrm{CBS}}+\frac{B}{\left(l_{\max }\right)^{3}}
$$

also might adhere to this phenomenon. To complicate matters further, using $l_{\max }=n+1$ fits for TM atoms and TM-containing molecules, we find $l_{\max }=n$ fits for main group atoms may overestimate the correlation energy by biasing the molecules with the $l_{\max }=n+1$ fits. We have computed MP2 CBS energies using a third fit,

$$
E(n)=E_{\mathrm{CBS}}+\frac{B}{\left(n+\frac{1}{2}\right)^{3}}
$$

which is a compromise between using $l_{\max }=n$ and $l_{\max }=n+$ 1 in eq 1.3. Unfortunately, this creates five different CBS energies to be examined with the additive ccCA corrections, but these extra steps are essential until more is known about TM CBS energies. To define the various ways to determine the CBS energies, "ccCA-S4" denotes ccCA energies computed with the CBS functional of eq 1.1, "ccCA-S3"refers to results from the CBS fit in eq 1.3, and "ccCA-S3+1/2" denotes CBS limits using eq 1.4. Once the MP2/CBS total energy is obtained, it is then modified with the following set of additive computations.

(a) A correction $[\triangle E(\mathrm{CC})]$ for correlation effects beyond second-order perturbation theory is evaluated using the method of coupled cluster utilizing single and double excitations with a perturbative triples contribution and a small basis set, namely, CCSD(T)/cc-pVTZ,

$$
\Delta E(\mathrm{CC})=E[\mathrm{CCSD}(\mathrm{T}) / \mathrm{cc}-\mathrm{pVTZ}]-E[\mathrm{MP} 2 / \mathrm{cc}-\mathrm{pVTZ}]
$$

(b) An adjustment $[\Delta E(\mathrm{CV})]$ for core valence correlation effects is made through an MP2(FC1)/aug-cc-pCVTZ computation,

$$
\begin{array}{r}
\Delta E(\mathrm{CV})=E[\mathrm{MP} 2(\mathrm{FC} 1) / \text { aug-cc-pCVTZ }]- \\
E[\mathrm{MP} 2 / \text { aug-cc-pVTZ }]
\end{array}
$$

where the G03 keyword "FC1" symbolizes that 1s molecular orbitals (MOs) remain frozen for molecules with second-row atoms and $1 \mathrm{~s} 2 \mathrm{~s} 2 \mathrm{p}$ MOs remain frozen for TM atoms. For TM atoms, the weighted core-valence aug-cc-pwCVTZ basis sets ${ }^{66}$ are used, and for main group atoms, the aug-cc-pCVTZ ${ }^{65}$ basis sets are used. Since two different basis sets are used in eq 1.6, it is possible that some valence-valence correlation from the additional tight core functions in the aug-cc-pCVTZ basis set may be double-counted in the MP2 CBS extrapolations. This potential effect is being considered in a study currently underway on main group molecules.

(c) A correction for scalar relativistic effects is computed using the cc-pVTZ-DK basis sets ${ }^{66,78}$ and the spin-free, oneelectron Douglas-Kroll-Hess (DKH) Hamiltonian. ${ }^{79-81}$ The MP2 relativistic correction to the ccCA energy is formulated as

$$
\begin{array}{r}
\Delta E(\mathrm{SR}-\mathrm{MP} 2)=E[\mathrm{MP} 2 / \mathrm{cc}-\mathrm{pVTZ}-\mathrm{DK}]- \\
E[\mathrm{MP} 2 / \mathrm{cc}-\mathrm{pVTZ}]
\end{array}
$$

4. The reference energy $(E(\mathrm{MP} 2 / \mathrm{CBS}))$ and the corrections from the previous steps are combined in an additive manner along with a spin-orbit correction $\left(\Delta E_{\mathrm{SO}}\right)$ for the atoms to give the ccCA energy

$$
\begin{aligned}
& E_{\mathrm{ccCA}-\mathrm{tm}}= E(\mathrm{MP} 2 / \mathrm{CBS})+\Delta E(\mathrm{CC})+\Delta E(\mathrm{CV})+ \\
& \Delta E(\mathrm{SR}-\mathrm{MP} 2)+\Delta E(\mathrm{ZPE})+\Delta E(\mathrm{SO})
\end{aligned}
$$

For selected systems, this ccCA-tm scheme will be compared to a $\operatorname{CCSD}(\mathrm{T})$ composite method comparable to the Dixon/ Feller/Peterson scheme for computing main-group molecular energies. ${ }^{29,30,32}$ Optimally, we would like the ccCA-tm to effectively reproduce the accuracy of this all-electron DKCCSD(T) CBS method. The DK-CCSD(T) scheme is outlined as follows. Consistent with earlier work, a reference energy is obtained by averaging the $\operatorname{CCSD}(\mathrm{T})$ total energies from two CBS extrapolation formulas, a three-point (TQ5) mixed Gaussian-exponential function ${ }^{82}$

$$
E(x)=A_{\mathrm{CBS}}+B \exp [-(n-1)]+C \exp \left[-(n-1)^{2}\right]
$$

and the two-point (Q5) Schwartz-like $n^{-3}$ extrapolation (eq 1.3) with aug-cc-pVnZ-DK basis sets. The aug-cc-pV(n+d)Z-DK sets were used for $\mathrm{Cl}^{59}$ The averaging of results from $\mathrm{n}=\mathrm{TQ} 5$ and $\mathrm{n}=\mathrm{Q} 5$ extrapolations previously has been shown to provide reliable relative energies for main group applications. ${ }^{83}$ In light of the comments briefly discussed above concerning $l_{\max }=n$ or $l_{\max }=n+1$ fits with eq 1.3, DK-CCSD(T) CBS correlation energies obtained using eq 1.4 with QZ and $5 \mathrm{Z}$ basis sets have also been investigated. In these cases, the resulting CBS limits were then added to the aug-cc-pV5Z-DK HF energies to obtain estimates of the CBS total energies. It should be noted that the $\mathrm{HF}$ atomization energies with this basis set are estimated to be within $0.1-0.2 \mathrm{kcal} / \mathrm{mol}$ of the HF limits for the species included in this section. Furthermore, the resulting DK-CCSD(T)/CBS atomization energies obtained with these two approaches differed by an average of just $0.47 \mathrm{kcal} / \mathrm{mol}$, with the method based on eq 1.4 yielding uniformly larger values. Below, we have adopted the latter values as our best estimates of the CBS limits. 
TABLE 1: Atomic Energies (in Hartrees) Used in the Computation of Molecular Enthalpies of Formation

\begin{tabular}{|c|c|c|c|c|c|}
\hline & $\mathrm{Ti}$ & V & $\mathrm{Cr}$ & $\mathrm{Mn}$ & $\mathrm{Fe}$ \\
\hline $\operatorname{ccCA}(\mathrm{S} 3 \mathrm{TQ})$ & -853.146193 & -948.594768 & -1050.181608 & -1157.955429 & -1272.008411 \\
\hline ccCA (S4 TQ) & -853.145951 & -948.594309 & -1050.180820 & -1157.954325 & -1272.006521 \\
\hline ccCA (S3 Q5) & -853.146702 & -948.595730 & -1050.183260 & -1157.957742 & -1272.012368 \\
\hline $\operatorname{ccCA}(\mathrm{S} 4 \mathrm{Q} 5)$ & -853.146324 & -948.595016 & -1050.182034 & -1157.956025 & -1272.009430 \\
\hline $\operatorname{ccCA}(\mathrm{S} 3+1 / 2 \mathrm{TQ})$ & -853.146446 & -948.595246 & -1050.182430 & -1157.956579 & -1272.010379 \\
\hline $\mathrm{DK}-\mathrm{CCSD}(\mathrm{T})$ & -853.165635 & -948.606471 & -1050.172503 & & -1271.988223 \\
\hline \multirow[t]{2}{*}{$\mathrm{SO}^{a}$} & -1.014 & -1.455 & 0.0 & 0.0 & -1.836 \\
\hline & $\mathrm{Co}$ & $\mathrm{Ni}$ & $\mathrm{Cu}$ & $\mathrm{Zn}$ & \\
\hline ccCA (S3 TQ) & -1392.625855 & -1519.935465 & -1654.160482 & -1795.289917 & \\
\hline ccCA (S4 TQ) & -1392.623137 & -1519.931922 & -1654.155865 & -1795.284838 & \\
\hline ccCA (S3 Q5) & -1392.631546 & -1519.942882 & -1654.170150 & -1795.300550 & \\
\hline ccCA (S4 Q5) & -1392.627321 & -1519.937375 & -1654.162972 & -1795.292655 & \\
\hline $\operatorname{ccCA}(\mathrm{S} 3+1 / 2 \mathrm{TQ})$ & -1392.628685 & -1519.939153 & -1654.165290 & -1795.295205 & \\
\hline $\mathrm{DK}-\mathrm{CCSD}(\mathrm{T})$ & -1392.595453 & -1519.896051 & -1654.093947 & & \\
\hline \multirow[t]{2}{*}{ SO } & -3.614 & -4.428 & 0.0 & 0.0 & \\
\hline & $\mathrm{H}$ & $\mathrm{C}$ & $\mathrm{O}$ & $\mathrm{F}$ & $\mathrm{Cl}$ \\
\hline $\operatorname{ccCA}(\mathrm{S} 3 \mathrm{TQ})^{b}$ & -0.499985 & -37.854444 & -75.114004 & -99.815539 & -461.420005 \\
\hline $\operatorname{ccCA}(\mathrm{S} 4 \mathrm{TQ})^{b}$ & -0.499985 & -37.853717 & -75.112056 & -99.812692 & -461.417702 \\
\hline $\operatorname{ccCA}(\mathrm{S} 3+1 / 2 \mathrm{TQ})$ & -0.499985 & -37.855202 & -75.116034 & -99.818505 & -461.422404 \\
\hline $\mathrm{DK}-\mathrm{CCSD}(\mathrm{T})$ & -0.500000 & -37.851617 & -75.110965 & -99.812501 & -461.392148 \\
\hline SO & 0.0 & -0.135 & -0.240 & -0.614 & -1.340 \\
\hline
\end{tabular}

${ }^{a}$ Atomic spin-orbit corrections are in $\mathrm{mE}_{\mathrm{h}} .{ }^{b}$ For main group atoms, the TQ energies are equivalent to Q5 energies. See text for details.

An additive correction for core-valence effects was also included and determined via

$$
\Delta E(\mathrm{CV})=E[\mathrm{CCSD}(\mathrm{T})](\mathrm{FC} 1)-E[\mathrm{CCSD}(\mathrm{T})]
$$

where both calculations were carried out with aug-cc-pwCVTZDK basis sets. In contrast to the ccCA-tm energies, the DK$\operatorname{CCSD}(\mathrm{T})$ approach used basis sets with added core-valence functions for both the FC1 and the valence computations in order to avoid the possible double counting mentioned earlier.

Finally, these calculations were carried out using geometries optimized at the DK-CCSD(T)/aug-cc-pVTZ-DK level of theory. All zero-point and thermal corrections were taken from the $\operatorname{SBKJC}(\mathrm{d}) / 6-31 \mathrm{G}(\mathrm{d})$ harmonic frequencies (scaled by 0.9684 ) described above. Open-shell DK-CCSD(T) energies were computed with the R/UCCSD(T) ${ }^{32,84,85}$ method using fully symmetry-equivalenced, restricted Hartree-Fock orbitals. All energies computed with the DK-CCSD(T) model chemistry utilized the Molpro 2002.6 program. ${ }^{86}$

\section{Results and Discussion}

Table 1 shows main-group and $3 \mathrm{~d}$ atomic energies computed with the ccCA-tm and DK-CCSD(T) composite methods. Energetic breakdowns of the atomic and molecular additive corrections are given as Supporting Information in Table S1. Table 2 shows experimental gas-phase enthalpies of formation for the test set of $17 \mathrm{TM}$ complexes. Many of the complexes are necessarily small as this represents the nature of TM complexes for which the most reliable gas-phase thermodynamic data from experiment is available. Examples incorporate 8 of the 10 3d TMs, excluding Sc and Mn.

Before deviations from experiment are analyzed, one important point can be discerned from an inspection of Table 2; the mean absolute deviation (MAD) of the experimental uncertainties themselves is $3.1 \mathrm{kcal} \mathrm{mol}^{-1}$ for the 17 molecules in our larger test set. This value is considerably high in relation to the experimental uncertainties in $\Delta H_{\mathrm{f}}{ }^{\circ}$ values for main group compounds, where uncertainties are a maximum of $\pm 1 \mathrm{kcal}$ $\mathrm{mol}^{-1}$ in the $\mathrm{G} 3 / 99$ set. $^{87}$
TABLE 2: Experimental Gas-Phase Enthalpies of Formation $^{a}$

\begin{tabular}{|c|c|c|}
\hline & $\begin{array}{l}\text { previous } \\
\text { theoretical value }\end{array}$ & $\begin{array}{l}\text { experimental } \\
\text { value } \pm \sigma\end{array}$ \\
\hline $\mathrm{TiO}_{2}$ & & $-73 \pm 3^{b}$ \\
\hline $\mathrm{TiF}_{2}$ & & $-164.5 \pm 10^{b}$ \\
\hline $\mathrm{TiF}_{3}$ & & $-284 \pm 10^{b}$ \\
\hline $\mathrm{TiCl}_{2}$ & & $-47.0 \pm 3.5^{c}$ \\
\hline VO & & $31.8 \pm 2.0^{d}$ \\
\hline $\mathrm{VO}_{2}$ & & $-41.6 \pm 3.3^{d}$ \\
\hline $\mathrm{CrO}_{3}$ & $-79.8^{e}$ & $\begin{array}{l}-77.3 \pm 1.0^{f} \\
-70.0^{g}\end{array}$ \\
\hline $\mathrm{FeCl}$ & $45.3^{h}$ & $49.5 \pm 1.6^{i}$ \\
\hline $\mathrm{FeCl}_{2}$ & $-35.8^{h}$ & $\begin{array}{l}-33.7 \pm 0.5^{b} \\
-32.8 \pm 1.6^{i}\end{array}$ \\
\hline $\mathrm{FeCl}_{3}$ & $-66.8^{h}$ & $-60.5 \pm 1.2^{b}$ \\
\hline $\mathrm{CoCl}_{3}$ & & $-39.1 \pm 2.5^{b}$ \\
\hline $\mathrm{NiCl}_{2}$ & & $-17.4 \pm 1.6^{i}$ \\
\hline $\mathrm{CuO}$ & & $\begin{array}{c}73.2 \pm 10^{b} \\
76.0 \pm 5^{j}\end{array}$ \\
\hline $\mathrm{CuF}$ & & $\begin{array}{c}-3 \pm 4^{b} \\
1.1 \pm 3^{k}\end{array}$ \\
\hline $\mathrm{CuF}_{2}$ & & $-63.8 \pm 1.3^{k}$ \\
\hline $\mathrm{Zn}\left(\mathrm{CH}_{3}\right)_{2}$ & & $12.6 \pm 1.4^{l}$ \\
\hline $\mathrm{Zn}\left(\mathrm{CH}_{2} \mathrm{CH}_{3}\right)_{2}$ & & $14 \pm 1.0^{l}$ \\
\hline
\end{tabular}

${ }^{a}$ Values are reported at $298.15 \mathrm{~K}$ with units of $\mathrm{kcal} \mathrm{mol}^{-1}$. When multiple experimental values are available, our preferred value (for calculation of deviations) is italicized. ${ }^{b}$ Reference $98 .{ }^{c}$ Reference 99. ${ }^{d}$ Reference 100. ${ }^{e}$ Reference 47, obtained from the average of G2 and PCI $-\mathrm{X}$ composite methods adapted for TM computations. ${ }^{f}$ Reference 93. ${ }^{g}$ Afeefy, H. Y.; Liebman, J. F.; Stein, S. E. Neutral Thermochemical Data. In NIST Chemistry WebBook, NIST Standard Reference Database, number 69; Mallard, W. G., Lindstrom, P. J., Eds.; National Institute of Standards and Technology: Gaithersburg, MD, 1998. ${ }^{h}$ Reference 97, recommended values from a QCISD(T) Wachters-based composite approach. ${ }^{i}$ Reference $101 .{ }^{j}$ Reference $102 .{ }^{k}$ Reference 103. ${ }^{l}$ Martinho Simões, J. A. Organometallic Thermochemistry Data. In NIST Chemistry WebBook, NIST Standard Reference Database, number 69, Linstrom, P. J., Mallard, W. G., Eds.; National Institute of Standards and Technology: Gaithersburg, MD, 2005.

Computational efficiency is, of course, key to applications for larger, more experimentally relevant TM complexes or even for small molecules in condensed phases. Thus, we have compared ccCA-tm to a more sophisticated, albeit, more 
TABLE 3: DK-CCSD(T) Enthalpies of Formation (in $\mathrm{kcal} \mathrm{mol}^{-1}$ ) and Contributions of Additive Corrections

\begin{tabular}{|c|c|c|c|c|c|c|c|c|c|c|}
\hline molecule & $\begin{array}{l}\text { aVTZ-DK } \\
\operatorname{CCSD}(\mathrm{T})\end{array}$ & $\begin{array}{l}\text { CBS-DK } \\
\text { CCSD(T) }\end{array}$ & $\Delta(\operatorname{Rel})$ & $\Delta(\mathrm{CV})$ & $\Delta(\mathrm{SO})$ & ZPE & $\begin{array}{c}\Delta H(\text { atomiz }), \\
0 \mathrm{~K}\end{array}$ & $\begin{array}{c}\Delta H_{\mathrm{f}}, \\
298 \mathrm{~K}\end{array}$ & $\begin{array}{l}\text { experimental } \\
\text { value }\end{array}$ & deviation \\
\hline $\mathrm{TiF}_{2}$ & 279.0 & 283.6 & 0.6 & 0.4 & -1.4 & -2.1 & 280.5 & -131.3 & $-164.5 \pm 10$ & -33.2 \\
\hline $\mathrm{TiF}_{3}$ & 425.6 & 432.6 & 1.4 & 0.4 & -1.8 & -3.7 & 427.6 & -260.2 & $-284 \pm 10$ & -23.8 \\
\hline $\mathrm{VO}$ & 144.9 & 149.8 & -0.6 & 1.9 & -1.1 & -1.3 & 149.4 & 32.0 & $31.8 \pm 2.0$ & -0.2 \\
\hline $\mathrm{VO}_{2}$ & 272.9 & 282.0 & 1.1 & 1.4 & -1.2 & -3.2 & 279.1 & -39.1 & $-41.6 \pm 3.3$ & -2.5 \\
\hline $\mathrm{CrO}_{3}$ & 329.1 & 341.6 & 8.3 & -0.7 & -0.5 & -5.6 & 334.9 & -64.3 & $-77.3 \pm 1.0$ & -13.0 \\
\hline $\mathrm{FeCl}_{2}$ & 185.5 & 193.7 & -3.1 & -0.9 & -2.8 & -1.3 & 188.6 & -32.5 & $-32.8 \pm 1.6$ & 0.3 \\
\hline $\mathrm{CoCl}_{3}$ & 221.1 & 223.2 & -0.3 & -0.1 & -4.8 & -2.1 & 223.3 & -35.9 & $-39.1 \pm 2.5$ & -3.2 \\
\hline $\mathrm{NiCl}_{2}$ & 174.2 & 182.1 & -3.0 & -1.8 & -4.5 & -1.4 & 174.5 & -14.9 & $-17.4 \pm 1.6$ & -2.5 \\
\hline $\mathrm{CuF}$ & 96.6 & 98.8 & -0.4 & -0.8 & -0.4 & -0.9 & 96.7 & 2.1 & $1.1 \pm 3$ & -1.0 \\
\hline $\mathrm{CuF}_{2}$ & 183.7 & 186.8 & 3.8 & -1.6 & -0.8 & -2.5 & 182.0 & -65.0 & $-63.8 \pm 1.3$ & 1.2 \\
\hline
\end{tabular}

TABLE 4: ccCA-tm Enthalpies of Formation (in $\mathrm{kcal} \mathrm{mol}^{-1}$ ) and Contributions of Additive Corrections

\begin{tabular}{|c|c|c|c|c|c|c|c|c|c|c|c|}
\hline molecule & aVQZ MP2 & $\begin{array}{l}\text { ccCA-S4 } \\
\text { (Q5) CBS }\end{array}$ & $\Delta(\mathrm{CC})$ & $\Delta(\operatorname{Rel})$ & $\Delta(\mathrm{CV})$ & $\Delta(\mathrm{SO})$ & ZPE & $\begin{array}{c}\Delta H(\text { atomiz) } \\
0 \mathrm{~K}\end{array}$ & $\begin{array}{c}\Delta H_{\mathrm{f}}, \\
298 \mathrm{~K}\end{array}$ & $\begin{array}{l}\text { experimental } \\
\text { value }\end{array}$ & deviation \\
\hline $\mathrm{TiO}_{2}$ & 334.3 & 342.5 & -40.8 & -0.4 & 11.9 & -0.9 & -3.2 & 309.0 & -79.0 & $-73 \pm 3$ & 6.0 \\
\hline $\mathrm{TiF}_{2}$ & 294.5 & 302.5 & -16.3 & 0.8 & 3.7 & -1.4 & -2.1 & 287.2 & -138.0 & $-164.5 \pm 10$ & -26.5 \\
\hline $\mathrm{TiF}_{3}$ & 449.0 & 461.0 & -23.2 & 1.6 & 0.7 & -1.8 & -3.7 & 434.5 & -267.1 & $-284 \pm 10$ & -16.9 \\
\hline $\mathrm{TiCl}_{2}$ & 224.8 & 232.3 & -8.9 & -0.6 & 2.2 & -2.3 & -1.2 & 221.5 & -51.5 & $-47.0 \pm 3.5$ & 4.5 \\
\hline VO & 121.6 & 125.1 & 21.2 & 1.6 & 8.3 & -1.1 & -1.4 & 153.6 & 27.7 & $31.8 \pm 2.0$ & 4.1 \\
\hline $\mathrm{VO}_{2}$ & 206.4 & 213.9 & 56.6 & 3.0 & 15.3 & -1.2 & -3.1 & 284.5 & -44.6 & $-41.6 \pm 3.3$ & 3.0 \\
\hline $\mathrm{CrO}_{3}$ & 444.2 & 456.1 & -114.8 & 6.4 & 11.0 & -0.5 & -5.6 & 352.6 & -82.0 & $-77.3 \pm 1.0$ & 4.7 \\
\hline $\mathrm{FeCl}$ & 88.7 & 92.4 & -7.2 & -2.2 & -0.9 & -2.0 & -0.5 & 79.7 & 47.8 & $49.5 \pm 1.6$ & 1.7 \\
\hline $\mathrm{FeCl}_{2}$ & 200.2 & 208.0 & -9.2 & -3.2 & -0.1 & -2.8 & -1.3 & 191.3 & -35.2 & $-32.8 \pm 1.6$ & 2.4 \\
\hline $\mathrm{FeCl}_{3}$ & 244.5 & 254.7 & -0.7 & 0.7 & -5.8 & -3.7 & -2.1 & 243.1 & -58.6 & $-60.5 \pm 1.2$ & -1.9 \\
\hline $\mathrm{CoCl}_{3}$ & 211.0 & 221.3 & 9.8 & 0.1 & -2.0 & -4.8 & -2.1 & 222.3 & -35.0 & $-39.1 \pm 2.5$ & -4.1 \\
\hline $\mathrm{NiCl}_{2}$ & 181.1 & 188.8 & -3.6 & -3.0 & 1.7 & -4.5 & -1.4 & 178.0 & -18.4 & $-17.4 \pm 1.6$ & 1.0 \\
\hline $\mathrm{CuO}$ & 64.6 & 68.0 & -2.6 & -2.1 & 0.3 & -0.2 & -1.0 & 62.5 & 76.8 & $76 \pm 5.0$ & -0.8 \\
\hline $\mathrm{CuF}$ & 107.5 & 111.8 & -8.2 & 0.0 & -0.5 & -0.4 & -0.9 & 101.8 & -3.0 & $1.1 \pm 3$ & 4.1 \\
\hline $\mathrm{CuF}_{2}$ & 174.7 & 182.0 & 8.8 & 3.9 & -14.7 & -0.8 & -2.4 & 176.8 & -59.8 & $-63.8 \pm 1.3$ & -4.0 \\
\hline $\mathrm{ZnMe}_{2}$ & 710.0 & 717.1 & -6.2 & -0.9 & 0.6 & -0.2 & -43.1 & 667.4 & 9.9 & $12.6 \pm 1.4$ & 2.7 \\
\hline $\mathrm{ZnEt}_{2}$ & 1289.8 & 1302.9 & -11.6 & -1.1 & 2.1 & -0.3 & -78.6 & 1213.2 & 7.5 & $14 \pm 1.0$ & 6.5 \\
\hline
\end{tabular}

computationally expensive, CBS/extended electron correlation method, DK-CCSD(T). Because of the large size of the correlation consistent TM basis sets, the DK-CCSD(T) method will be computationally challenging for even modestly sized systems containing a TM atom and $>10$ nonhydrogen atoms. Contributions of the CBS extrapolations, scalar relativistic effects, core-valence correlation effects, and atomic spin-orbit effects to the DK-CCSD(T) $\Delta H_{\mathrm{f}}$ values are given in Table 3. The DK-CCSD $(\mathrm{T})$ enthalpies of formation have been calculated for a 10 molecule subset of the ccCA-tm training set. The average of these 10 experimental uncertainties is $3.6 \mathrm{kcal} \mathrm{mol}^{-1}$. All DK-CCSD(T) $\Delta H_{\mathrm{f}}$ values are within twice the experimental error bars except for $\mathrm{TiF}_{2}, \mathrm{TiF}_{3}$, and $\mathrm{CrO}_{3}$. The mean signed deviation for DK-CCSD(T) has a large magnitude, $-7.9 \mathrm{kcal}$ $\mathrm{mol}^{-1}$, while the MAD is $8.2 \mathrm{kcal} \mathrm{mol}^{-1}$, suggesting that there is a systematic underestimation of the magnitude of the enthalpy of formation for the DK-CCSD(T) composite method.

For the 17 molecules in the full ccCA-tm training set, as well as the 10 molecule DK-CCSD(T) subset, contributions of ccCAtm additive effects are given in Table 4 for one CBS extrapolation scheme (ccCA-S4 Q5), while CBS atomization energies are given in Table 5 for the other four extrapolation schemes. Some signed deviations, such as ccCA-tm with the ccCA-S4 (TQ) and ccCA-S4 (Q5) extrapolations appear to show less bias for the subset. For comparison, mean signed and absolute deviations are given for DK-CCSD $(\mathrm{T})$ and the variants of ccCA$\mathrm{tm}$ in Table 4. Of the five ccCA-tm variations, the ccCA-S4 (Q5) CBS fit is initially the most reliable, as it predicts 8 of the $10 \Delta H_{\mathrm{f}}$ values to within $2 \sigma$ ( $\sigma$ is the reported experimental uncertainty in the enthalpy of formation) of the experimental values and has a small signed mean deviation of $-3.2 \mathrm{kcal}$ $\mathrm{mol}^{-1}$ and a MAD of $7.1 \mathrm{kcal} \mathrm{mol}^{-1}$ (see Table 6). Figure 1 pictorially shows the differences between the ccCA-tm and the
DK-CCSD(T) model chemistries for the training subset. The DK-CCSD(T) aug-cc-pVTZ geometry optimizations of the 10 molecules for which DK-CCSD(T) energies have been computed are similar to the B3LYP SBKJC(d)/6-31G(d) geometries of the ccCA-tm method. Bond lengths agree to at least $0.05 \AA$, and bond angles agree to within $3^{\circ}$. The occasionally significant differences in $\Delta H_{\mathrm{f}}$ cannot be attributed to these relatively small geometric variants.

In spite of the difference between ccCA-tm and DK$\operatorname{CCSD}(\mathrm{T})$ energies, the theoretical $\Delta H_{\mathrm{f}}$ values do bring into question some experimental results. For $\mathrm{TiF}_{2}$, the calculated enthalpies of formation are 25 and $34 \mathrm{kcal} \mathrm{mol}^{-1}$ too high for DK-CCSD(T), and ccCA-tm absolute deviations range from 13 to $33 \mathrm{kcal} \mathrm{mol}^{-1}$ depending on the basis set extrapolation scheme that is employed. The experimental $\mathrm{TiF}_{2}$ value is in fact taken from a reaction involving $\mathrm{TiF}_{3}$; therefore, any problems with the experimental $\mathrm{TiF}_{3}$ value would propagate to the $\mathrm{TiF}_{2}$ experimental $\Delta H_{\mathrm{f}}$ value. The large overestimation of the $\Delta H_{\mathrm{f}}$ values using $\mathrm{DK}-\mathrm{CCSD}(\mathrm{T})$ and most variations of ccCA-tm suggests that their experimental gas-phase enthalpies of formation should be re-examined. If $\mathrm{TiF}_{2}$ and $\mathrm{TiF}_{3}$ are removed from the training subset, the DK-CCSD(T) and ccCA model chemistries perform much better for the eight remaining compounds (whose experimental $\sigma$ averages $2.0 \mathrm{kcal} \mathrm{mol}^{-1}$ ): the DKCCSD(T) MAD is $3.1 \mathrm{kcal} \mathrm{mol}^{-1}$, and the best ccCA-tm MAD, again with the $\mathrm{S} 4$ (Q5) extrapolation, is $3.4 \mathrm{kcal} \mathrm{mol}^{-1}$. These MAD values are commensurate with the estimates of "TM chemical accuracy" (vide infra) for enthalpies of formation.

If $\mathrm{TiF}_{2}$ and $\mathrm{TiF}_{3}$ are removed from the larger ccCA-tm test set, $15 \mathrm{TM}$ species remain. While the average of experimental uncertainties is decreased without the $\mathrm{TiF}_{x}$ compounds (from $3.1 \mathrm{kcal} \mathrm{mol}^{-1}$ to $2.2 \mathrm{kcal} \mathrm{mol}^{-1}$ ), the accuracy of ccCA-tm remains nearly equivalent within the smaller training set. Four 
TABLE 5: ccCA-tm Enthalpies of Formation (in kcal mol ${ }^{-1}$ ) with the Various CBS Extrapolations

\begin{tabular}{|c|c|c|c|c|c|}
\hline molecule & $\begin{array}{l}\text { ccCA-S3 } \\
\text { (TQ) CBS }\end{array}$ & $\begin{array}{c}\Delta H(\text { atomiz }), \\
0 \mathrm{~K}\end{array}$ & $\begin{array}{c}\Delta H_{\mathrm{f}}, \\
298 \mathrm{~K}\end{array}$ & $\begin{array}{l}\text { experimental } \\
\text { value }\end{array}$ & deviation \\
\hline $\mathrm{TiO}_{2}$ & 338.3 & 304.7 & -74.8 & $-73 \pm 3$ & 1.8 \\
\hline $\mathrm{TiF}_{2}$ & 296.8 & 281.4 & -132.2 & $-164.5 \pm 10$ & -32.3 \\
\hline $\mathrm{TiF}_{3}$ & 452.3 & 425.9 & -258.5 & $-284 \pm 10$ & -25.5 \\
\hline $\mathrm{TiCl}_{2}$ & 227.5 & 216.7 & -46.8 & $-47.0 \pm 3.5$ & -0.2 \\
\hline VO & 123.0 & 151.6 & 29.7 & $31.8 \pm 2.0$ & 2.1 \\
\hline $\mathrm{VO}_{2}$ & 209.8 & 280.3 & -40.4 & $-41.6 \pm 3.3$ & -1.2 \\
\hline $\mathrm{CrO}_{3}$ & 449.8 & 346.3 & -75.7 & $-77.3 \pm 1.0$ & -1.6 \\
\hline $\mathrm{FeCl}$ & 90.0 & 77.3 & 50.2 & $49.5 \pm 1.6$ & -0.7 \\
\hline $\mathrm{FeCl}_{2}$ & 203.2 & 186.5 & -30.4 & $-32.8 \pm 1.6$ & -2.4 \\
\hline $\mathrm{FeCl}_{3}$ & 247.7 & 236.1 & -51.6 & $-60.5 \pm 1.2$ & -8.9 \\
\hline $\mathrm{CoCl}_{3}$ & 214.3 & 215.3 & -28.0 & $-39.1 \pm 2.5$ & -11.1 \\
\hline $\mathrm{NiCl}_{2}$ & 184.0 & 173.2 & -13.7 & $-17.4 \pm 1.6$ & -3.7 \\
\hline $\mathrm{CuO}$ & 66.0 & 60.4 & 78.9 & $76 \pm 5.0$ & -2.9 \\
\hline $\mathrm{CuF}$ & 108.9 & 98.9 & -0.1 & $1.1 \pm 3$ & 1.2 \\
\hline $\mathrm{CuF}_{2}$ & 176.3 & 171.1 & -54.1 & $-63.8 \pm 1.3$ & -9.7 \\
\hline $\mathrm{ZnMe}_{2}$ & 715.2 & 665.4 & 11.9 & $12.6 \pm 1.4$ & 0.7 \\
\hline $\mathrm{ZnEt}_{2}$ & 1299.0 & 1209.4 & 11.3 & $14 \pm 1.0$ & 2.7 \\
\hline molecule & $\begin{array}{l}\text { ccCA-S3 } \\
\text { (Q5) CBS }\end{array}$ & $\begin{array}{c}\Delta H(\text { atomiz }), \\
0 \mathrm{~K}\end{array}$ & $\begin{array}{l}\Delta H_{\mathrm{f}} \\
298 \mathrm{~K}\end{array}$ & $\begin{array}{l}\text { experimental } \\
\text { value }\end{array}$ & deviation \\
\hline $\mathrm{TiO}_{2}$ & 337.5 & 303.9 & -73.9 & $-73 \pm 3$ & 0.9 \\
\hline $\mathrm{TiF}_{2}$ & 296.3 & 280.9 & -131.7 & $-164.5 \pm 10$ & -32.8 \\
\hline $\mathrm{TiF}_{3}$ & 451.6 & 425.2 & -257.8 & $-284 \pm 10$ & -26.2 \\
\hline $\mathrm{TiCl}_{2}$ & 226.9 & 216.2 & -46.2 & $-47.0 \pm 3.5$ & -0.8 \\
\hline VO & 122.7 & 151.3 & 30.1 & $31.8 \pm 2.0$ & 1.7 \\
\hline $\mathrm{VO}_{2}$ & 209.1 & 279.6 & -39.7 & $-41.6 \pm 3.3$ & -1.9 \\
\hline $\mathrm{CrO}_{3}$ & 448.6 & 345.2 & -74.5 & $-77.3 \pm 1.0$ & -2.8 \\
\hline $\mathrm{FeCl}$ & 89.7 & 77.0 & 50.4 & $49.5 \pm 1.6$ & -0.9 \\
\hline $\mathrm{FeCl}_{2}$ & 202.6 & 185.8 & -29.8 & $-32.8 \pm 1.6$ & -3.0 \\
\hline $\mathrm{FeCl}_{3}$ & 247.0 & 235.5 & -51.0 & $-60.5 \pm 1.2$ & -9.5 \\
\hline $\mathrm{CoCl}_{3}$ & 213.6 & 214.6 & -27.3 & $-39.1 \pm 2.5$ & -11.8 \\
\hline $\mathrm{NiCl}_{2}$ & 183.4 & 172.6 & -13.1 & $-17.4 \pm 1.6$ & -4.3 \\
\hline $\mathrm{CuO}$ & 65.7 & 60.1 & 79.2 & $76 \pm 5.0$ & -3.2 \\
\hline $\mathrm{CuF}$ & 108.6 & 98.6 & 0.2 & $1.1 \pm 3$ & 0.9 \\
\hline $\mathrm{CuF}_{2}$ & 176.0 & 170.8 & -53.7 & $-63.8 \pm 1.3$ & -10.1 \\
\hline $\mathrm{ZnMe}_{2}$ & 714.1 & 664.3 & 12.9 & $12.6 \pm 1.4$ & -0.3 \\
\hline $\mathrm{ZnEt}_{2}$ & 1297.2 & 1207.6 & 13.2 & $14 \pm 1.0$ & 0.8 \\
\hline molecule & $\begin{array}{l}\text { ccCA-S4 } \\
\text { (TQ) CBS }\end{array}$ & $\begin{array}{c}\Delta H(\text { atomiz }), \\
0 \mathrm{~K}\end{array}$ & $\begin{array}{l}\Delta H_{\mathrm{f}}, \\
298 \mathrm{~K}\end{array}$ & $\begin{array}{l}\text { experimental } \\
\text { value }\end{array}$ & deviation \\
\hline $\mathrm{TiO}_{2}$ & 345.2 & 311.6 & -81.7 & $-73 \pm 3$ & 8.7 \\
\hline $\mathrm{TiF}_{2}$ & 5.3 & 289.9 & -140.7 & $-164.5 \pm 10$ & -23.8 \\
\hline $\mathrm{TiF}_{3}$ & 465.0 & 438.6 & -271.2 & $-284 \pm 10$ & -12.8 \\
\hline $\mathrm{TiCl}_{2}$ & 234.8 & 224.0 & -54.0 & $-47.0 \pm 3.5$ & 7.0 \\
\hline VO & 126.2 & 154.8 & 26.5 & $31.8 \pm 2.0$ & 5.3 \\
\hline $\mathrm{VO}_{2}$ & 216.4 & 286.9 & -47.0 & $-41.6 \pm 3.3$ & 5.4 \\
\hline $\mathrm{CrO}_{3}$ & 459.9 & 356.4 & -85.8 & $-77.3 \pm 1.0$ & 8.5 \\
\hline $\mathrm{FeCl}$ & 93.6 & 80.9 & 46.6 & $49.5 \pm 1.6$ & 2.9 \\
\hline $\mathrm{FeCl}_{2}$ & 210.5 & 193.8 & -37.7 & $-32.8 \pm 1.6$ & 4.9 \\
\hline $\mathrm{FeCl}_{3}$ & 258.1 & 246.5 & -62.0 & $-60.5 \pm 1.2$ & 1.5 \\
\hline $\mathrm{CoCl}_{3}$ & 224.8 & 225.8 & -38.5 & $-39.1 \pm 2.5$ & -0.6 \\
\hline $\mathrm{NiCl}_{2}$ & 191.4 & 180.5 & -21.0 & $-17.4 \pm 1.6$ & 3.6 \\
\hline $\mathrm{CuO}$ & 69.2 & 63.6 & 75.7 & $76 \pm 5.0$ & 0.3 \\
\hline $\mathrm{CuF}$ & 113.2 & 103.2 & -4.4 & $1.1 \pm 3$ & 5.5 \\
\hline $\mathrm{CuF}_{2}$ & 184.5 & 179.3 & -62.3 & $-63.8 \pm 1.3$ & -1.5 \\
\hline $\mathrm{ZnMe}_{2}$ & 719.3 & 669.5 & 7.7 & $12.6 \pm 1.4$ & 4.9 \\
\hline $\mathrm{ZnEt}_{2}$ & 1306.8 & 1217.2 & 3.6 & $14 \pm 1.0$ & 10.4 \\
\hline molecule & $\begin{array}{c}\mathrm{ccCA}-\mathrm{S} 3+1 / 2 \\
\mathrm{CBS}\end{array}$ & $\begin{array}{c}12 \Delta H \text { (atomiz), } \\
0 \mathrm{~K}\end{array}$ & $\begin{array}{l}\Delta H_{\mathrm{f}}, \\
298 \mathrm{~K}\end{array}$ & $\begin{array}{l}\text { experimental } \\
\text { value }\end{array}$ & deviation \\
\hline $\mathrm{TiO}_{2}$ & 339.3 & 305.7 & -75.8 & $-73 \pm 3$ & 2.7 \\
\hline $\mathrm{TiF}_{2}$ & 97.3 & 282.0 & -132.8 & $-164.5 \pm 10$ & -31.8 \\
\hline $\mathrm{TiF}_{3}$ & 453.2 & 426.7 & -259.3 & $-284 \pm 10$ & -24.8 \\
\hline $\mathrm{TiCl}_{2}$ & 228.2 & 217.4 & -47.5 & $-47.0 \pm 3.5$ & 0.4 \\
\hline VO & 123.4 & 151.9 & 29.4 & $31.8 \pm 2.0$ & 2.4 \\
\hline $\mathrm{VO}_{2}$ & 210.6 & 281.1 & -41.2 & $-41.6 \pm 3.3$ & -0.4 \\
\hline $\mathrm{CrO}_{3}$ & 450.9 & 347.5 & -76.8 & $-77.3 \pm 1.0$ & -0.4 \\
\hline $\mathrm{FeCl}$ & 90.3 & 77.6 & 49.9 & $49.5 \pm 1.6$ & -0.4 \\
\hline $\mathrm{FeCl}_{2}$ & 203.8 & 187.1 & -31.0 & $-32.8 \pm 1.6$ & -1.8 \\
\hline $\mathrm{FeCl}_{3}$ & 248.3 & 236.7 & -52.2 & $-60.5 \pm 1.2$ & -8.2 \\
\hline $\mathrm{CoCl}_{3}$ & 214.9 & 215.9 & -28.6 & $-39.1 \pm 2.5$ & -10.4 \\
\hline $\mathrm{NiCl}_{2}$ & 184.6 & 173.8 & -14.2 & $-17.4 \pm 1.6$ & -3.1 \\
\hline $\mathrm{CuO}$ & 66.3 & 60.7 & 78.6 & $76 \pm 5.0$ & -2.6 \\
\hline $\mathrm{CuF}$ & 109.2 & 99.2 & -0.4 & $1.1 \pm 3$ & 1.5 \\
\hline $\mathrm{CuF}_{2}$ & 176.7 & 171.5 & -54.4 & $-63.8 \pm 1.3$ & -9.4 \\
\hline $\mathrm{ZnMe}_{2}$ & 716.1 & 666.4 & 10.9 & $12.6 \pm 1.4$ & 1.8 \\
\hline $\mathrm{ZnEt}_{2}$ & 1300.7 & 1211.1 & 9.7 & $14 \pm 1.0$ & 4.6 \\
\hline
\end{tabular}

TABLE 6: Overall Signed and Unsigned Mean Deviations (in kcal mol ${ }^{-1}$ ) for the Training Sets with ccCA-tm and DK-CCSD(T) Composite Methods

\begin{tabular}{|c|c|c|c|c|}
\hline & $\begin{array}{c}\text { DK- } \\
\text { CCSD(T) } \\
\text { test set }\end{array}$ & $\begin{array}{c}\text { DK-CCSD }(\mathrm{T}) \\
\text { test set } \mathrm{w} / \mathrm{o} \\
\mathrm{TiF}_{2} \& \mathrm{TiF}_{3}\end{array}$ & $\begin{array}{l}\text { ccCA-tm } \\
\text { test set }\end{array}$ & $\begin{array}{c}\text { ccCA-tm } \\
\text { test set w/o } \\
\mathrm{TiF}_{2} \& \mathrm{TiF}_{3}\end{array}$ \\
\hline no. of species & 10 & 8 & 17 & 15 \\
\hline $\begin{array}{l}\text { ccCA-S3 (TQ) dev } \\
\text { ccCA-S3 (Q5) dev } \\
\text { ccCA-S4 (TQ) dev } \\
\text { ccCA-S4 (Q5) dev } \\
\text { ccCA-S3+1/2 dev } \\
\text { DK-CCSD(T) dev }\end{array}$ & $\begin{array}{l}-8.4 \\
-9.0 \\
-0.6 \\
-3.2 \\
-7.8 \\
-7.9\end{array}$ & $\begin{array}{r}-3.3 \\
-3.9 \\
3.9 \\
1.4 \\
-2.7 \\
-2.8\end{array}$ & $\begin{array}{r}-5.4 \\
-6.1 \\
1.8 \\
-0.8 \\
-4.7\end{array}$ & $\begin{array}{r}-2.3 \\
-3.0 \\
4.5 \\
2.0 \\
-1.6\end{array}$ \\
\hline $\begin{array}{l}\text { ccCA-S3 (TQ) MAD } \\
\text { ccCA-S3 (Q5) MAD } \\
\text { ccCA-S4 (TQ) MAD } \\
\text { ccCA-S4 (Q5) MAD } \\
\text { ccCA-S3+1/2 MAD } \\
\text { DK-CCSD(T) MAD } \\
\sigma \text { of experimental } \\
\text { uncertainties }\end{array}$ & $\begin{array}{l}9.1 \\
9.6 \\
7.2 \\
7.1 \\
8.6 \\
8.2 \\
3.6\end{array}$ & $\begin{array}{l}4.1 \\
4.6 \\
4.4 \\
3.4 \\
3.7 \\
3.1 \\
2.0\end{array}$ & $\begin{array}{l}6.4 \\
6.6 \\
6.3 \\
5.6 \\
6.3\end{array}$ & $\begin{array}{l}3.4 \\
3.5 \\
4.7 \\
3.4 \\
3.3\end{array}$ \\
\hline
\end{tabular}

of the CBS extrapolations have MADs between 3.3 and $3.5 \mathrm{kcal}$ $\mathrm{mol}^{-1}$. Using the average experimental $\sigma$ of $\pm 2-3 \mathrm{kcal} \mathrm{mol}^{-1}$ as an initial estimate of "TM chemical accuracy," we find that ccCA-tm thus performs adequately for this test set and is quite superior to DFT-based methods. ${ }^{38,45}$

Cognizance must be taken of the potential for issues in the modeling of $3 \mathrm{~d}$ TM complexes that arise from the underlying perturbation theory assumptions of many of the ccCA-tm computations. Such computations may not provide an accurate description of both static and dynamic electron correlation, and problems can arise from the inherently multireference nature of many TM species. ${ }^{40,41,88,89}$ The open-shell $D_{1}$ diagnostic defined by Lee ${ }^{90}$ is based on previous $D_{1} / T_{1}$ diagnostics ${ }^{91,92}$ and attempts to give a mathematically rigorous indication of the quality of an open-shell coupled cluster wave function. Analysis of the amplitude diagnostics as well as the maximum values of the amplitudes can provide a sense for the multireference character of a molecule. A $T_{1}$ diagnostic or maximum $T_{1}$ amplitude greater than 0.05 indicates some multireference character to the wave function. Lee's work implies that $D_{1}$ diagnostic values greater than 0.1 also correspond to a multireference wave function. Open- and closed-shell $D_{1}$ diagnostics are given for the 10 molecule DK-CCSD(T) subset in Table 7. Further supporting the idea that $\mathrm{TiF}_{2}$ and $\mathrm{TiF}_{3}$ should be reexamined experimentally is that these two molecules have the lowest $T_{1} / D_{1}$ diagnostics of the set, as well as very small maximum $T_{1}$ or $T_{2}$ amplitudes. This indicates that the pertur-

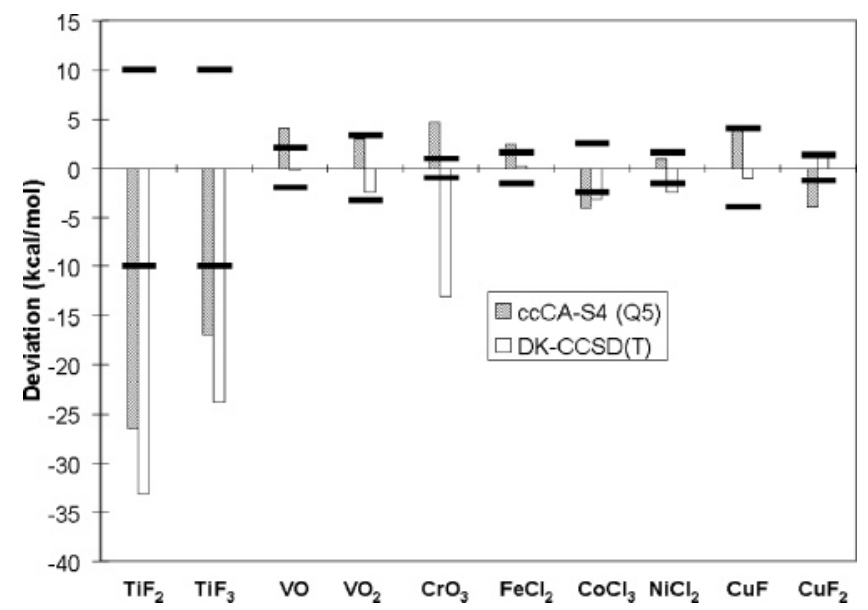

Figure 1. Graphical comparison of errors in $\Delta H_{\mathrm{f}}$ with the ccCA-S4 (Q5) and DK-CCSD(T) model chemistries for the 10 molecules studied with both methods. 
TABLE 7: $T_{1}$ and $D_{1}$ Diagnostics and Maximum $T_{n}$ Amplitudes for the 10 Molecule DK-CCSD(T) Subset Using CCSD cc-pVTZ Coupled Cluster Amplitudes

\begin{tabular}{lcccc}
\hline molecule & $\begin{array}{c}T_{1} \\
\text { diagnostic }\end{array}$ & $\begin{array}{c}D_{1} \\
\text { diagnostic }\end{array}$ & $\begin{array}{c}\text { max } T_{1} \\
\text { amplitude }\end{array}$ & $\begin{array}{c}\max T_{2} \\
\text { amplitude }\end{array}$ \\
\hline $\mathrm{TiF}_{2}$ & 0.023 & 0.052 & 0.06 & $<0.05$ \\
$\mathrm{TiF}_{3}$ & 0.024 & 0.052 & 0.05 & $<0.05$ \\
$\mathrm{VO}$ & 0.055 & 0.098 & 0.10 & $<0.05$ \\
$\mathrm{VO}_{2}$ & 0.064 & 0.165 & 0.18 & 0.07 \\
$\mathrm{CrO}_{3}$ & 0.055 & 0.198 & 0.16 & 0.08 \\
$\mathrm{FeCl}_{2}$ & 0.026 & 0.058 & 0.08 & $<0.05$ \\
$\mathrm{CoCl}_{3}$ & 0.061 & 0.177 & 0.22 & 0.06 \\
$\mathrm{NiCl}_{2}$ & 0.040 & 0.124 & 0.18 & 0.10 \\
$\mathrm{CuF}$ & 0.035 & 0.133 & 0.09 & $<0.05$ \\
$\mathrm{CuF}_{2}$ & 0.027 & 0.099 & 0.14 & $<0.05$
\end{tabular}

bative and coupled cluster wave functions for the $\mathrm{TiF}_{x}$ systems are relatively well-described. Five of the 10 molecules have a $D_{1}$ diagnostic over 0.1 and a maximum $T_{1}$ amplitude over 0.05 . The $\mathrm{CrO}_{3}$ molecule has the largest $D_{1}$ diagnostic as well as the largest DK-CCSD(T) error (excluding the $\mathrm{TiF}_{x}$ systems), suggesting a relationship between the quality of the molecular reference HF wave function and the deviation in $\Delta H_{\mathrm{f}}$ values.

Though the ccCA-S4 (Q5) enthalpies of formation appear to perform well, it is very interesting that for almost every value in the 10 molecule subset, ccCA-tm and DK-CCSD(T) values lie on opposite sides of the error bars; that is, when DK$\mathrm{CCSD}(\mathrm{T})$ values are lower than experiment, ccCA-S4 (Q5) values are higher than experiment, and vice versa. We hypothesize that issues with the MP2 energies and the $\Delta(\mathrm{CC})$ additive correction may be the cause of differences in the calculated $\Delta H_{\mathrm{f}}$ values between the ccCA-tm and the DK-CCSD(T) composite methods. The contributions to dissociation energies of the ccCA $\Delta(\mathrm{CC})$ correction are quite large (in Table 4) and can be up to $115 \mathrm{kcal} \mathrm{mol}^{-1}$ for $\mathrm{CrO}_{3}$. For 7 of the 17 species, the $\Delta(\mathrm{CC})$ contribution is greater than $10 \mathrm{kcal} \mathrm{mol}^{-1}$. It is likely that this correction is sensitive to both dynamical and nondynamical electron correlation, as well as spin contamination within the UHF reference wave functions. In addition, calculation of $\Delta$ (CV) at the MP2 level of theory tends to significantly overestimate this contribution compared to DK-CCSD(T). Lack of $5 \mathrm{Z}$ basis sets in the determination of the ccCA-tm CBS limits is not a likely source of error; tests based on the DK-CCSD(T) results indicate that the use of TQ correlation energies instead of Q5 led to an overestimation of the atomization energies by an average of just $0.5 \mathrm{kcal} / \mathrm{mol}$. Neglect of molecular spinorbit coupling in our investigation could also contribute to the deviations from experiment.

Also of note is the comparison of the ccCA-tm and DKCCSD(T) methods with previous composite methods. An investigation of the $\mathrm{CrO}_{3}$ enthalpy of formation using a G2like procedure carried out by Espelid et al. ${ }^{47}$ gave a substantially different $\Delta H_{\mathrm{f}}(298.15 \mathrm{~K})$ than either the ccCA-tm or the DKCCSD(T) result. Surprisingly, the two composite methods originating from this study seem to bracket the most recent experimental value ${ }^{93}$ obtained by Ebbinghaus by almost $7 \mathrm{kcal}$ mol $^{-1}$, while an average of the PCI-X (a parametrized method of computing correlation energies developed by Siegbahn and

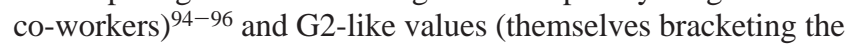
experimental value by -3 and $+9 \mathrm{kcal} \mathrm{mol}^{-1}$, respectively) are quite close to the experimental value of $-77.3 \mathrm{kcal} \mathrm{mol}^{-1} \cdot{ }^{93} \mathrm{~A}$ composite method created by Bach and co-workers ${ }^{97}$ using QCISD(T) and Wachters basis sets was applied to iron chloride systems and gave average errors of $3 \mathrm{kcal} \mathrm{mol}^{-1}$ for $\mathrm{FeCl}, \mathrm{FeCl}_{2}$, and $\mathrm{FeCl}_{3}$. The ccCA-S4 (Q5) $\Delta H_{\mathrm{f}}$ values for the three iron chlorides are better, averaging a $2 \mathrm{kcal} \mathrm{mol}^{-1}$ deviation.
The initial implementation of ccCA-tm has difficulty accurately computing $\Delta H_{\mathrm{f}}$ values of larger TM complexes. Curiously, the best ccCA CBS extrapolation (S4 Q5) performs quite poorly for dimethyl and diethyl zinc, with a deviation of 2.7 and $6.5 \mathrm{kcal} \mathrm{mol}^{-1}$, respectively. The ccCA-S3 fits, however, do quite well, with the ccCA-S3 Q5 extrapolation within the experimental error bars for both molecules. Another example of ccCA-tm performing unsatisfactorily is in the modeling of larger TM carbonyls; for example, for $\mathrm{Ni}(\mathrm{CO})_{4}, \mathrm{Fe}(\mathrm{CO})_{5}$, and $\mathrm{Cr}(\mathrm{CO})_{6}$, ccCA-tm shows errors of $30-100 \mathrm{kcal} \mathrm{mol}^{-1}$. While consolation may be taken in the fact that the ccCA-tm deviations for carbonyl systems are still much smaller than those obtained using standard DFT/ECP approaches, ${ }^{45}$ further work is necessary to determine whether the disagreement is caused by deterioration of ccCA-tm with respect to increasing molecular size or by something inherent in carbonyl or related $\pi$-acid ligands. Our initial observations suggest an intriguing origin for these discrepancies, as a more sophisticated treatment of the corevalence electron correlation substantially improves the calculated $\Delta H_{\mathrm{f}}{ }^{\circ}$ for carbonyl complexes. Interestingly, the DK-CCSD(T) composite method suffers less from degradation in accuracy upon increasing the system size, on the basis of the example of $\mathrm{Ni}(\mathrm{CO})_{4}$, where the DK-CCSD(T) method is in error by $5 \mathrm{kcal}$ $\mathrm{mol}^{-1}$ versus $50 \mathrm{kcal} \mathrm{mol}^{-1}$ with ccCA-tm, although the DK$\operatorname{CCSD}(\mathrm{T})$ calculated enthalpy of formation (computed with standard valence cc-pVnZ basis sets rather than their augmented counterparts) is more than three times the experimental uncertainty as well. Determining potential solutions to the problems observed with carbonyl-containing molecules, including a modification of ccCA-tm, is currently underway for the carbonyls as well as a more diverse set of ligands.

\section{Conclusions}

Both ccCA-tm and DK-CCSD(T) approaches give results near our conservative estimate of "TM chemical accuracy" of \pm 3 $\mathrm{kcal} \mathrm{mol}^{-1}$. It must be re-iterated that ccCA-tm requires significantly less computational resources than DK-CCSD(T), as the ccCA-tm bottleneck computation is either a $\operatorname{CCSD}(\mathrm{T}) /$ cc-pVTZ or an MP2/aug-cc-pVQZ computation for the former composite method versus a DK-CCSD(T)/aug-cc-pV5Z (or an aug-cc-pVQZ) computation for the latter. However, the effective level of theory obtained from the additive ccCA corrections does not seem to match that explicitly computed with the DK-CCSD(T) method, as calculated ccCA-S4 (Q5) enthalpies of formation tend to lie on opposite sides of the experimental error bars compared with the DK-CCSD(T) approach. The DK-CCSD(T) and ccCA-tm $\Delta H_{\mathrm{f}}$ values are different by more than $19 \mathrm{kcal}$ $\mathrm{mol}^{-1}$ in the case of $\mathrm{CrO}_{3}$.

In summary, novel methods have been created for modeling TM thermodynamics. Minimal changes are needed to be made to the standard ccCA methodology, applied with success to sand p-block compounds. ${ }^{33-36}$ The only substantial change is the use of ECP basis sets for initial geometry optimization, a change incorporated to permit future access to second and third row TM complexes. While these preliminary results are exciting, challenges remain in producing a reliable and "black box" approach to computational TM composite methods. From a chemical perspective, the correlation consistent basis sets allow access to accurate computation of thermodynamic properties for compounds incorporating elements from the $s, \mathrm{p}$, and $\mathrm{d}$ blocks. Forthcoming developments in the correlation consistent family of basis sets will allow any model chemistries utilizing them to access chemical compounds incorporating elements from across the entire periodic table. The DK-CCSD(T) and 
ccCA-tm composite methods represent the first step in a significant improvement over DFT methods in predictive accuracy for a chemically diverse array of TM chemical compounds. Research is underway to improve the reliability of the ccCA-tm methodology without sacrificing computational efficiency. We also hope to expand our training set to create a formal G3/05-type training set with more stringent criteria with regards to the experimental uncertainties, as well as include energetic parameters such as ionization potentials, bond energies, electron affinities, and excitation energies. Finally, we hope that these first, promising steps toward chemically accurate thermodynamics for TM complexes will inspire complementary experimental studies, as such data from both the computational and the experimental arenas are essential to make good the longpromised goals such as the rational design of catalysts.

Acknowledgment. CASCaM is supported by a grant from the U.S. Department of Education. This research is partially supported by a grant from the U.S. Department of Energy, Office of Basic Energy Sciences (to T.R.C.), Grant No. DE-FG0203ER15387, and by a National Science Foundation CAREER Award CHE-0239555 (to A.K.W.). Additional support was also provided by the University of North Texas (UNT) Academic Computing Services for the use of the UNT Research Cluster. Computational resources were provided via the National Science Foundation (CHE-0342824) and by the National Computational Science Alliance under \#CHE010021 and utilized the NCSA IBM p690. Computations employed the UNT computational chemistry resource, whose purchase was supported by a CRIF grant by the National Science Foundation (CHE-0342824). G.S. thanks the University of the Free State for support, as well as the South African National Research Foundation (NRF, Grant No. GUN 2068915) and the Innovation Fund. The authors would like to thank Sammer Tekarli for assistance with the electronic configurations of the iron chloride species.

Supporting Information Available: Details of the geometric and energetic data for all molecular species. This material is available free of charge via the Internet at http://pubs.acs.org.

\section{References and Notes}

(1) Curtiss, L. A.; Redfern, P. C.; Frurip, D. J. In Reviews of Computational Chemistry; Lipkowitz, K. B., Boyd, D. B., Eds.; WileyVCH: New York, 2000; Vol. 15, p 147.

(2) Curtiss, L. A.; Raghavachari, K.; Redfern, P. C.; Rassolov, V.; Pople, J. A. J. Chem. Phys. 1998, 109, 7764.

(3) Curtiss, L. A.; Raghavachari, K. Theor. Chem. Acc. 2002, 108, 61

(4) Baboul, A. G.; Curtiss, L. A.; Redfern, P. C.; Raghavachari, K. J. Chem. Phys. 1999, 110, 7650.

(5) Curtiss, L. A.; Redfern, P. C.; Raghavachari, K.; Pople, J. A. J. Chem. Phys. 2001, 114, 108.

(6) Petersson, G. A.; Frisch, M. J. J. Phys. Chem. A 2000, 104, 2183.

(7) Montgomery, J. A.; Frisch, M. J.; Ochterski, J. W.; Petersson, G. A. J. Chem. Phys. 1999, 110, 2822.

(8) Petersson, G. A. Abstr. Am. Chem. Soc. 1996, 212, 175.

(9) Ochterski, J. W.; Petersson, G. A.; Montgomery, J. A. J. Chem. Phys. 1996, 104, 2598

(10) East, A. L. L.; Allen, W. D. J. Chem. Phys. 1993, 99, 4638.

(11) Kenny, J. P.; Allen, W. D.; Schaefer, H. F. J. Chem. Phys. 2003, 118,7353 .

(12) Gonzales, J. M.; Pak, C.; Cox, R. S.; Allen, W. D.; Schaefer, H. F.; Császár, A. G.; Tarczay, G. Chem-Eur. J. 2003, 9, 2173.

(13) Császár, A. G.; Allen, W. D.; Schaefer, H. F. J. Chem. Phys. 1998, 108,9751

(14) Császár, A. G.; Allen, W. D.; Yamaguchi, Y.; Schaefer, H. F. In Computational Molecular Spectroscopy; Jensen, P., Bunker, P. R., Eds.; John Wiley \& Sons, Ltd.: New York, 2000; p 15.

(15) Császár, A. G.; Szalay, P. G.; Leininger, M. L. Mol. Phys. 2002, 100,3879 .

(16) Császár, A. G.; Leininger, M. L.; Burcat, A. J. Phys. Chem. A 2003, 107,2061
(17) Császár, A. G.; Leininger, M. L.; Szalay, V. J. Chem. Phys. 2003, $118,10631$.

(18) Parthiban, S.; Martin, J. M. L. J. Chem. Phys. 2001, 114, 6014.

(19) Martin, J. M. L.; Oliveira, G. de J. Chem. Phys. 1999, 111, 1843.

(20) Boese, A. D.; Oren, M.; Atasoylu, O.; Martin, J. M. L.; Kallay, M.; Gauss, J. J. Chem. Phys. 2004, 120, 4129.

(21) Karton, A.; Rabinovich, E.; Martin, J. M. L.; Ruscic, B. J. Chem. Phys. 2006, 125.

(22) Szalay, P. G.; Tajti, A.; Stanton, J. F. Mol. Phys. 2005, 103, 2159.

(23) Tajti, A.; Szalay, P. G.; Császár, A. G.; Kallay, M.; Gauss, J.; Valeev, E. F.; Flowers, B. A.; Vazquez, J.; Stanton, J. F. J. Chem. Phys. 2004, 121, 11599

(24) Feller, D.; Dixon, D. A. J. Phys. Chem. A 2003, 107, 9641

(25) Feller, D.; Dixon, D. A.; Francisco, J. S. J. Phys. Chem. A 2003 , 107, 1604

(26) Feller, D.; Peterson, K. A.; de Jong, W. A.; Dixon, D. A. J. Chem Phys. 2003, 118, 3510.

(27) Dixon, D. A.; Feller, D.; Francisco, J. S. J. Phys. Chem. A 2003, 107, 186.

(28) Dixon, D. A.; Feller, D.; Peterson, K. A. J. Chem. Phys. 2001, 115,2576

(29) Feller, D.; Dixon, D. A. J. Phys. Chem. A 2000, 104, 3048.

(30) Dixon, D. A.; Feller, D.; Sandrone, G. J. Phys. Chem. A 1999 103,4744

(31) Feller, D.; Dixon, D. A. J. Phys. Chem. A 1999, 103, 6413.

(32) Pollack, L.; Windus, T. L.; de Jong, W. A.; Dixon, D. A. J. Phys. Chem. A 2005, 109, 6934.

(33) DeYonker, N. J.; Cundari, T. R.; Wilson, A. K. J. Chem. Phys. 2006, 124, 114104.

(34) DeYonker, N. J.; Cundari, T. R.; Wilson, A. K.; Sood, C. A.; Magers, D. H. THEOCHEM 2006, 775, 77.

(35) DeYonker, N. J.; Grimes, T.; Yockel, S.; Dinescu, A.; Mintz, B.; Cundari, T. R.; Wilson, A. K. J. Chem. Phys. 2006, 125, 104111

(36) Ho, D. S.; DeYonker, N. J.; Wilson, A. K.; Cundari, T. R. J. Phys. Chem. A 2006, 110, 9767.

(37) Curtiss, L. A.; Redfern, P. C.; Raghavachari, K. J. Chem. Phys. 2005, 123, 124017

(38) Furche, F.; Perdew, J. P. J. Chem. Phys. 2006, 124

(39) Schultz, N. E.; Zhao, Y.; Truhlar, D. G. J. Phys. Chem. A 2005 $109,11127$.

(40) Gerenkamp, M.; Grimme, S. Chem. Phys. Lett. 2004, 392, 229

(41) Hyla-Kryspin, I.; Grimme, S. Organometallics 2004, 23, 5581.

(42) Nielsen, I. M. B.; Allendorf, M. D. J. Phys. Chem. A 2006, 110 , 4093.

(43) Nielsen, I. M. B.; Allendorf, M. A. J. Phys. Chem. A 2005, 109, 928.

(44) Quintal, M. M.; Karton, A.; Iron, M. A.; Boese, A. D.; Martin, J.

M. L. J. Phys. Chem. A 2006, 110, 709 .

(45) Cundari, T. R.; Leza, H. A. R.; Grimes, T.; Steyl, G.; Waters, A.; Wilson, A. K. Chem. Phys. Lett. 2005, 401, 58

(46) Zhao, Y.; Truhlar, D. G. J. Chem. Phys. 2006, 124

(47) Espelid, O.; Borve, K. J.; Jensen, V. R. J. Phys. Chem. A 1998, 102,10414 .

(48) Burda, J. V.; Zeizinger, M.; Sponer, J.; Leszczynski, J. J. Chem. Phys. 2000, 113, 2224

(49) Munk, B. H.; Schlegel, H. B. Chem. Mater. 2006, 18, 1878. 7522 .

(51) Sullivan, M. B.; Iron, M. A.; Redfern, P. C.; Martin, J. M. L.; Curtiss, L. A.; Radom, L. J. Phys. Chem. A 2003, 107, 5617.

(52) DeYonker, N. J.; Ho, D. S.; Wilson, A. K.; Cundari, T. R. in preparation.

(53) Curtiss, L. A.; Raghavachari, K.; Redfern, P. C.; Pople, J. A. J. Chem. Phys. 1997, 106, 1063.

(54) Feller, D.; Peterson, K. A. J. Chem. Phys. 1998, 108, 154.

(55) Frisch, M. J.; Trucks, G. W.; Schlegel, H. B.; Scuseria, G. E.; Robb, M. A.; Cheeseman, J. R.; Montgomery, J. A., Jr.; Vreven, T.; Kudin, K. N.; Burant, J. C.; Millam, J. M.; Iyengar, S. S.; Tomasi, J.; Barone, V.; Mennucci, B.; Cossi, M.; Scalmani, G.; Rega, N.; Petersson, G. A.; Nakatsuji, H.; Hada, M.; Ehara, M.; Toyota, K.; Fukuda, R.; Hasegawa, J.; Ishida, M.; Nakajima, T.; Honda, Y.; Kitao, O.; Nakai, H.; Klene, M.; Li, X.; Knox, J. E.; Hratchian, H. P.; Cross, J. B.; Bakken, V.; Adamo, C.; Jaramillo, J.; Gomperts, R.; Stratmann, R. E.; Yazyev, O.; Austin, A. J.; Cammi, R.; Pomelli, C.; Ochterski, J. W.; Ayala, P. Y.; Morokuma, K.; Voth, G. A.; Salvador, P.; Dannenberg, J. J.; Zakrzewski, V. G.; Dapprich, S.; Daniels, A. D.; Strain, M. C.; Farkas, O.; Malick, D. K.; Rabuck, A. D.; Raghavachari, K.; Foresman, J. B.; Ortiz, J. V.; Cui, Q.; Baboul, A. G.; Clifford, S.; Cioslowski, J.; Stefanov, B. B.; Liu, G.; Liashenko, A.; Piskorz, P.; Komaromi, I.; Martin, R. L.; Fox, D. J.; Keith, T.; Al-Laham, M. A.; Peng, C. Y.; Nanayakkara, A.; Challacombe, M.; Gill, P. M. W.; Johnson, B.; Chen, W.; Wong, M. W.; Gonzalez, C.; Pople, J. A. Gaussian 03, revision C.02; Gaussian, Inc.: Wallingford, CT, 2004 
Thermochemistry of Transition Metal Species

(56) Stevens, W. J.; Basch, H.; Krauss, M. J. Chem. Phys. 1984, 81, 6026.

(57) The recommended B3LYP CEP-31G scale factor is obtained from the CCCBDB data base at http://srdata.nist.gov/cccbdb.

(58) Dunning, T. H., Jr. J. Chem. Phys. 1989, 90, 1007.

(59) Dunning, T. H., Jr.; Peterson, K. A.; Wilson, A. K. J. Chem. Phys. 2001, 14, 9244.

(60) Wilson, A. K.; Woon, D. E.; Peterson, K. A.; Dunning, T. H., Jr.

J. Chem. Phys. 1999, 110, 7667.

(61) Wilson, A. K.; Woon, D. E.; Peterson, K. A.; Dunning, T. H., Jr. Abstr. Am. Chem. Soc. 1997, 213, 60.

(62) Kendall, R. A.; Dunning, T. H., Jr.; Harrison, R. J. J. Chem. Phys. 1992, 96, 6796.

(63) Woon, D. E.; Dunning, T. H., Jr. J. Chem. Phys. 1994, 100, 2975.

(64) Woon, D. E.; Dunning, T. H., Jr. J. Chem. Phys. 1995, 103, 4572.

(65) Peterson, K. A. Dunning, T. H., Jr. J. Chem. Phys, 2002, 117 10548

(66) Balabanov, N. B.; Peterson, K. A. J. Chem. Phys. 2005, 123, 064107.

(67) Yockel, S.; Wilson, A. K. Theor. Chem. Acc. in press.

(68) Halkier, A.; Helgaker, T.; Jorgensen, P.; Klopper, W.; Olsen, J. Chem. Phys. Lett. 1999, 302, 437.

(69) Feller, D. J. Chem. Phys. 1993, 98, 7059.

(70) Feller, D. J. Chem. Phys. 1992, 96, 6104.

(71) Schwartz, C. Phys. Rev. A 1962, 126, 1015.

(72) Schwartz, C. In Methods in Computational Physics; B. J. Alder, B. J., Fernbach, S., Rotenberg, M., Eds.; Academic Press: New York, 1963; Vol. 2, p 262.

(73) Kutzelnigg, W.; Morgan, J. D. J. Chem. Phys. 1992, 96, 4484.

(74) Martin, J. M. L. Chem. Phys. Lett. 1996, 259, 669.

(75) Helgaker, T.; Klopper, W.; Koch, H.; Noga, J. J. Chem. Phys. 1997, $106,9639$.

(76) Martin, J. M. L.; Lee, T. J. Chem. Phys. Lett. 1996, 258, 136.

(77) Halkier, A.; Helgaker, T.; Jorgensen, P.; Klopper, W.; Koch, H.;

Olsen, J.; Wilson, A. K. Chem. Phys. Lett. 1998, 286, 243.

(78) de Jong, W. A.; Harrison, R. J.; Dixon, D. A. J. Chem. Phys. 2001, $114,48$.

(79) Hess, B. A. Phys. Rev. A 1986, 33, 3742.

(80) Hess, B. A. Phys. Rev. A 1985, 32, 756.

(81) Douglas, M.; Kroll, N. M. Ann. Phys. (Leipzig) 1974, 82, 89.
(82) Peterson, K. A.; Woon, D. E.; Dunning, T. H., Jr. J. Chem. Phys. 1994, 100, 7410.

(83) Feller, D.; Peterson, K. A.; Crawford, T. D. J. Chem. Phys. 2006, 124.

(84) Rittby, M.; Bartlett, R. J. J. Phys. Chem. 1988, 92, 3033.

(85) Watts, J. D.; Gauss, J.; Bartlett, R. J. J. Chem. Phys. 1993, 98, 8718.

(86) Amos, R. D.; Bernhardsson, A.; Berning, A.; Celani, P.; Cooper, D. L.; Deegan, M. J. O.; Dobbyn, A. J.; Eckert, F.; Hampel, C.; Hetzer, G.; Knowles, P. J.; Korona, T.; Lindh, R.; Lloyd, A. W.; McNicholas, S. J.; Manby, F. R.; Meyer, W.; Mura, M. E.; Nicklass, A.; Palmieri, P.; Pitzer, R. M.; Rauhut, G.; Schütz, M.; Schumann, U.; Stoll, H.; Stone, A. J.; Tarroni, R.; Thorsteinsson, T.; Werner, H. J. MOLPRO, version 2002.6; University of Birmingham: Birmingham, U.K., 2002.

(87) Curtiss, L. A.; Raghavachari, K.; Redfern, P. C.; Pople, J. A. J. Chem. Phys. 2000, 112, 7374.

(88) Niu, S. Q.; Hall, M. B. J. Am. Chem. Soc. 1997, 119, 3077.

(89) Ricca, A.; Bauschlicher, J. C. W.; Rosi, M. J. Phys. Chem. 1994, 98, 9498.

(90) Lee, T. J. Chem. Phys. Lett. 2003, 372, 362.

(91) Lee, T. J.; Scuseria, G. E. In Quantum Mechanical Electron Structure Calculations with Chemical Accuracy; Langhoff, S. R., Ed.; Kluwer: Dordrecht, The Netherlands, 1995; p 47.

(92) Janssen, C. L.; Nielsen, I. M. B. Chem. Phys. Lett. 1998, 290, 423.

(93) Ebbinghaus, B. B. Combust. Flame 1993, 93, 119.

(94) Blomberg, M. R. A.; Siegbahn, P. E. M.; Svensson, M. J. Chem Phys. 1996, 104

(95) Siegbahn, P. E. M.; Blomberg, M. R. A.; Svensson, M. Chem. Phys. Lett. 1994, 223, 35

(96) Siegbahn, P. E. M.; Svensson, M.; Boussard, P. J. J. Chem. Phys. 1995, 102, 5377 .

(97) Bach, R. D.; Shobe, D. S.; Schlegel, H. B.; Nagel, C. J. J. Phys. Chem. 1996, 100, 8770.

(98) Chase, J. M. W.; Davies, C. A.; Downey, J. J. R.; Frurip, D. J.; McDonald, R. A.; Syverud, A. N. NIST-JANAF Tables, 4th ed.; J. Phys. Chem. Ref. Data, Mono. 9, Suppl.1, 1998.

(99) Hildenbrand, D. L. High Temp. Mater. Sci. 1996, 35, 151.

(100) Balducci, G.; Gigli, G.; Guido, M. J. Chem. Phys. 1983, 79, 5616

(101) Hildenbrand, D. L. J. Chem. Phys. 1995, 103, 2634.

(102) Pedley, J. B.; Marshall, E. M. J. Phys. Chem. Ref. Data 1983, 12,967

(103) Ehlert, T. C.; Wang, J. S. J. Phys. Chem. 1973, 81, 2069. 